\title{
Early work on apoptosis, an interview with Sten Orrenius
}

\author{
S Orrenius $\mathbf{s}^{*, 1}$ \\ ${ }^{1}$ Institute of Environmental Medicine, Division of Toxicology, Karolinska \\ Institutet, Box 210, SE-171 77 Stockholm, Sweden \\ * Corresponding author: S Orrenius, Institute of Environmental Medicine, \\ Division of Toxicology, Karolinska Institutet, Box 210, SE-171 77 Stockholm, \\ Sweden. Tel: + 468524875 90; Fax: + 4683290 41; \\ E-mail: sten.orrenius@ki.se \\ Cell Death and Differentiation (2006) 13, 1-4. \\ doi:10.1038/sj.cdd.4401810
}

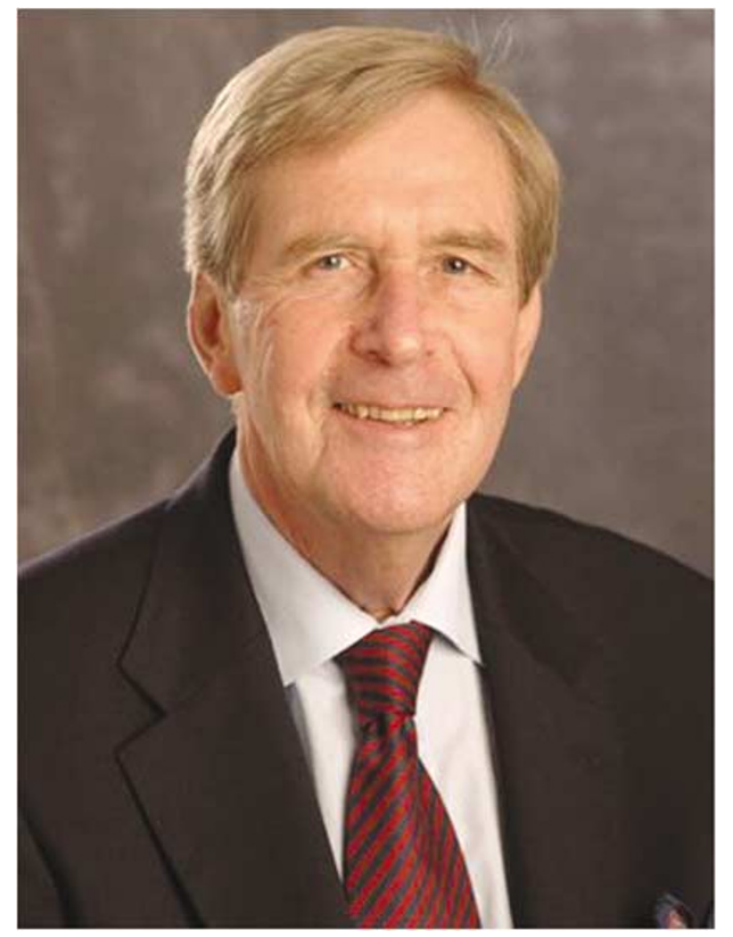

\section{About the author}

Sten Orrenius received his Ph.D. from Karolinska Institutet in Stockholm, Sweden in 1965 and his M.D. from the same institution in 1967. He has been on the staff of Karolinska Institutet in various positions since 1967. He was Professor of Forensic Medicine 1971-1984, when he was appointed Professor of Toxicology. He was also Dean of the Medical School 1980-1987. Dr. Orrenius is currently a member of several editorial boards, including Experimental Cell Research, Biochemical and Biophysical Research Communications, and Cell Death and Differentiation. He is also a member of several professional societies, including the Swedish Medical Association, and the Swedish Society for Toxicology. He holds honorary memberships in the American Society for Pharmacology and Experimental Therapeutics, the American Society for Biochemistry and Molecular Biology, and the
Society of Toxicology (USA). He is also a member of the Royal Swedish Academy of Sciences and a Foreign Associate Member of the Institute of Medicine of the National Academy of Sciences, USA. He has received honorary doctorates from the Universities of Stockholm, Turin, Konstanz, Buenos Aires and Paris V. In 2003, Dr. Orrenius was the recipient of the first ECDO Career Award for Excellence in Cell Death Research by the European Cell Death Organization.

Sten Orrenius was one the first scientists working on mechanisms involved in apoptotic cell death. In particular, his early work in this area was dedicated to the role of calcium and endonucleases in the killing of immature thymocytes by glucocorticoids. But how did it all begin? What triggered his scientific interest in this field? Here, Cell Death and Differentiation asks Sten Orrenius about the early work on apoptosis.

\section{CDD: What was your scientific interest before working on cell death?}

My interest in science started with my Ph.D. studies, which were performed mainly at the Wenner-Gren Institute for Experimental Biology of the University of Stockholm (1961-1965). My thesis supervisor, Professor Lars Ernster Ph.D. was head of the Division of Physiological Chemistry, and the research focus of his unit was on mitochondria and their role in cellular energy metabolism. However, Lars Ernster had also developed an interest in the structure and functions of the endoplasmic reticulum during a sabbatical with Philip Siekevitz and George Palade at the Rockefeller Institute in New York, and my work started with a subfractionation of liver microsomes and characterization of the enzymatic composition of the subfractions. ${ }^{1} \mathrm{~A}$ few years earlier, working at the Johnson Foundation in Philadelphia, Martin Klingenberg had discovered the CO-binding pigment of liver microsomes, ${ }^{2}$ later termed cytochrome P-450, and Ronald Estabrook and his colleagues had demonstrated its role as the terminal oxidase in steroid hydroxylation catalyzed by adrenal cortex microsomes. ${ }^{3}$ My early studies indicated that cytochrome P-450 served a similar function in oxidative drug metabolism in liver microsomes, ${ }^{4}$ and a detailed characterization of the microsomal drug hydroxylating enzyme system was part of my thesis work. ${ }^{5}$ These studies also led to the discovery of the induction of cytochrome P-450 in liver microsomes of experimental animals treated with certain drugs, notably phenobarbital, or carcinogens, that is, methylcholanthrene, and characterization of the enzyme induction process and its relationship to the concomitant proliferation of the liver endoplasmic reticulum membranes was the second part of my thesis work. ${ }^{6-8}$

I then spent my postdoc with John Schenkman in the Department of Pharmacology at Yale University and with Ron Estabrook in the Biochemistry Department at the Southwestern Medical School at Dallas, characterizing the 
cytochrome P-450 system and its substrate specificity in liver and extra-hepatic tissues in further detail.

\section{CDD: When did your work on cell death begin?}

After moving to the Department of Forensic Medicine at Karolinska Institutet in 1971, my research became more toxicologically oriented. Many cytotoxic and carcinogenic metabolites had been shown to be generated by cytochrome P-450-mediated reactions, and intracellular glutathione had been found to be of critical importance for cellular defence against such reactive metabolites. Following the pioneering studies of Brodie, Gillette and colleagues, bromobenzene and acetaminophen had become frequently used model compounds in studies of mechanisms of drug-induced hepatotoxicity. ${ }^{9}$ At this time, working with Peter Moldéus at the Karolinska, we had developed methodology to isolate suspensions of rat hepatocytes, which remained perfectly viable for many hours and could be used for studies of the generation, inactivation and cytotoxic effects of reactive intermediates from bromobenzene, acetaminophen and several other hepatotoxic drugs. ${ }^{10}$ This experimental system was also used for studies of the biosynthesis and metabolism of glutathione and glutathione conjugates, and together with Dean Jones, who was a postdoc in our group at this time, we could reconstitute the entire sequence of reactions involved in acetaminophen metabolism using a combination of freshly isolated hepatocytes, intestinal and renal cells. ${ }^{11}$

These early studies did not only reveal the critical importance of glutathione conjugation in cell defence, but also demonstrated the role of the calcium ion as a mediator of cytotoxicity. This became even more obvious in subsequent studies of oxidative cell damage using isolated hepatocytes and various redox-cycling quinones, notably menadione. ${ }^{12}$ Detailed studies of menadione toxicity in hepatocytes together with Giorgio Bellomo and Pierluigi Nicotera, who had both joined our group at this time, demonstrated that this was due to a combination of thiol oxidation and perturbation of intracellular calcium ion homeostasis triggered by the generation of reactive oxygen species during redox-cycling of the quinone. The cytoskeleton was found to be a particularly vulnerable target of menadione toxicity, and the formation of characteristic surface blebs on the hepatocytes could be ascribed to disruption of the normal organization of the miocrofilament system caused by the oxidation of thiol groups in actin and the activation of $\mathrm{Ca}^{2+}$-dependent proteolysis. ${ }^{13,14}$ Our early calcium work included studies of intracellular $\mathrm{Ca}^{2+}$ compartmentalization and signaling, notably nuclear calcium fluxes, ${ }^{15}$ and the cytoprotective effect of $\mathrm{Ca}^{2+}$-buffering by the mitochondria. ${ }^{16} \mathrm{~A}$ study of $\mathrm{Ca}^{2+}$-activated DNA fragmentation in liver nuclei can be seen as an early link to our future work on apoptotic cell death. ${ }^{17}$

\section{CDD: When did you first hear about apoptosis?}

Since I was trained as a pathologist, I was confronted with the characteristic morphology of apoptotic cell death already in medical school. However, the apoptosis concept of Kerr, Wyllie and Currie had not been developed at this time, and I first learned about it through their early publications in the 1970 s. ${ }^{18}$ Like most colleagues, I did not realize the importance of their discovery until later, but looked upon apoptosis as just another form of cell death. A turning point was my first meeting with Andrew Wyllie some 10 years later. The Society of Toxicology had organized an American-European debate on mechanisms of cell injury and death at their annual meeting in New Orleans in 1986, and Andrew and I had been selected as the European representatives. At the meeting, I discussed our recent work on the role of calcium in cell injury, and Andrew talked about apoptosis. I was fascinated by his presentation and decided to start working on apoptotic cell death. Back in Stockholm, I told my group about this exciting research area, and David McConkey, who was then a fresh graduate student in the laboratory, volunteered to go to Edinburgh to learn how to measure apoptosis in Andrew Wyllie's laboratory. This marked our entry into the apoptosis field.

\section{CDD: So tell us about your early work on apoptosis?}

Our early work concerned glucocorticoid-induced apoptosis in human thymocytes. We obtained the tissue from our thoracic surgery clinic; young infants in need of corrective cardiovascular surgery had their thymuses removed before the operation to make this possible. The initial studies were an extension of our previous work on $\mathrm{Ca}^{2+}$-mediated endonuclease activation in liver nuclei, and the working hypothesis was that a similar process was responsible for apoptotic cell death in thymocytes. ${ }^{19}$ At this time apoptosis research was pretty much focused on nuclear changes (nuclear apoptosis), and there was a search for endonucleases that could be held responsible for the DNA fragmentation seen in apoptotic cell death. It was also assumed that apoptotic endonuclease(s) would be calcium dependent. Andrew Wyllie had described such an activity in glucocorticoid-treated thymocytes and suggested that it was responsible for DNA ladder formation, ${ }^{20}$ and we had seen a characteristic apoptotic DNA fragmentation pattern in isolated liver nuclei incubated with calcium and ATP. Several other studies of thymocyte apoptosis had also concluded that the process was calcium dependent. ${ }^{21}$ This research resulted in a growing list of nucleases which could possibly be linked to apoptotic DNA fragmentation. However, the problem was not solved until we learned about the existence of a caspase-activated nuclease through the work of Wang and Nagata and their colleagues. ${ }^{22,23}$

\section{CDD: What happened then?}

Our studies were gradually extended to other cell types and triggers of apoptosis. In collaboration with Nancy Thornberry and Don Nicholson and their colleagues at Merck, we performed an early study on CPP32/Apopain, later termed caspase-3, in Fas-mediated apoptosis, ${ }^{24}$ which was followed by detailed investigations of the role of the growing caspase family in apoptosis together with Boris Zhivotovsky, who had 
joined the group at this time. Further, when Andrew Slater moved from a postdoc at the Rockefeller to the Karolinska we carried out a series of studies on the modulation of the apoptotic process by oxidants/antioxidants. ${ }^{25,26}$ These studies led to a growing interest in the role of the mitochondria in the regulation of apoptosis, which has been a major research topic in our laboratory ever since.

\section{CDD: How did you get interested in mitochondria?}

Our work on the role of mitochondria in cell damage and death started with early studies on mitochondrial calcium metabolism and the protective effect of mitochondrial calcium buffering against oxidative cell damage. ${ }^{16}$ Using the same experimental model, we could also show that inhibitors of mitochondrial permeability transition protected from oxidative cell injury under certain conditions. After Wang and colleagues had discovered the mitochondrial pathway of caspase activation, ${ }^{27}$ our work on the mitochondrial regulation of cell death was intensified. In collaboration with Stein-Ove Doskeland and his team at the University of Bergen in Norway, Boris Zhivotovsky characterized the apoptotic process triggered by microinjection of cytochrome $c$ into a variety of cell types in detail. ${ }^{28,29}$ From these studies, it was clear that presence of the intact hemoprotein in the soluble cytoplasm was enough for caspase activation and apoptotic cell death. Much of the lag phase seen in noninvasive models of apoptosis was gone, although Bcl-2 over-expressing cells proved to be less sensitive to apoptosis triggered by cytochrome $c$ injection. Following this study, much of our work on mitochondrial regulation of apoptosis has focused on mechanisms of cytochrome $c$ release and the relative contribution of proapoptotic $\mathrm{Bcl}-2$ family proteins and $\mathrm{Ca}^{2+}$-activated permeability transition to cytochrome $c$ release in various experimental systems. In collaboration with Vladimir Gogvadze, who joined our group a few years ago, we have characterized these release mechanisms in detail. ${ }^{30}$ More recent studies have focused on the detachment of cytochrome $c$ from its binding to the outer surface of the mitochondrial inner membrane as a necessary first step in the release process. ${ }^{31}$ The finding that this detachment is promoted by the peroxidation of the unique mitochondrial phospholipid, cardiolipin, is in accordance with early studies on cytochrome $c$ - cardiolipin interaction and with many recent reports on the influence of the cardiolipin status on the susceptibility of cells to apoptosis. ${ }^{32}$ Our recent work with John Robertson and Mari Enoksson on the permeabilization of mitochondria by processed caspase-2 also suggests that cardiolipin is critically involved in the regulation of cytochrome $c$ release. ${ }^{33,34}$ The interaction between cytochrome $\mathrm{c}$ and cardiolipin is the subject for ongoing studies in our laboratory.

\section{CDD: Are there any clinical implications of this work, and how does it affect modern toxicology?}

There are potential clinical implications of all work on mechanisms and regulation of apoptosis. For example, we know that apoptosis is a major mechanism by which both ionizing radiation and chemotherapy kill malignant cells, and knowing more about this process and how it is modulated is important for the development of novel and more efficient therapeutical approaches. On the other hand, toxic cell death has traditionally been regarded as being of the necrotic type. However, it is now increasingly clear that many toxicants kill cells by apoptosis, particularly at lower doses, or influence the susceptibility of cells to other triggers of apoptosis. Thus, knowledge of apoptotic mechanisms, and how they might be affected by chemicals, is of growing importance for toxicology and risk assessment.

\section{CDD: How did you manage to attract so many qualified collaborators, who have since made their own careers in the cell death field?}

I have been extremely lucky with a large number of very talented young scientists, who have spent time with me as graduate students, postdocs or visiting research fellows. If I restrict myself to our time in apoptosis research, David McConkey and Pierluigi Nicotera were members of the original research group, when we decided to start working in this area. David is probably the most productive student I ever had and published a large number of studies in high-ranking scientific journals before he graduated and moved back to the United States for a postdoc at Dana-Farber Cancer Institute at Harvard. Pierluigi was instrumental for the early work on calcium compartmentalization and $\mathrm{Ca}^{2+}$-activated endonucleases. He also developed our first CNS models for the study of neuronal cell death, ${ }^{35}$ but was subsequently recruited to a chair at the University of Konstanz when the Karolinska failed to offer him a permanent position. Finally, I met Boris Zhivotovsky at a cell death symposium in Budapest and managed to convince him to come to the Karolinska as a visiting scientist. Luckily, he never returned to St Petersburg, but succeeded me as head of the Division of Toxicology when I retired 2 years ago. Since Boris arrived we have collaborated on almost all aspects of apoptosis and, in addition, he has built his own group on apoptosis and cancer.

\section{CDD: Have you had time to engage in other academic activities?}

Yes, for many years I was actively involved in faculty work at Karolinska Institutet, and during 7 years I was dean of the medical school (1983-1990). For more than 30 years (19712202) I was also member of the Nobel Assembly at Karolinska Institutet, and during most of this time I also served on its Nobel Committee. The Nobel work provides you with a broad exposure to scientific progress in the whole field of biomedical science, which is invaluable also for your own scientific activities. Needless to say, the award of the Nobel Prize to Sydney Brenner, Robert Horvitz and John Sulston for their discoveries concerning 'genetic regulation of organ development and programmed cell death' was a highlight during my time in the Nobel Assembly. 


\section{CDD: What is your preference in terms of non-scientific interests?}

I must admit that work has consumed most of my time and that, apart from spending time with my family, working in the garden and seing friends; I do not have any time-consuming hobbies. A car accident during my military service many years ago has restricted my physical activity and made exercises that I used to enjoy not possible any more.

\section{Acknowledgements}

Sten Orrenius is grateful to the funding bodies that supported this work, in particular the Swedish Medical Research Council. He is indebted to many colleagues who made invaluable contributions to the work discussed above, but he would especially like to acknowledge the inspiration, insights, advice and warm friendship of his scientific mentor, Professor Lars Ernster (1920-1998).

1. Dallner G, Orrenius S and Bergstrand A (1963) J. Cell Biol. 16: 426-430

2. Klingenberg M (1958) Arch. Biochem. Biophys. 75: 376-386

3. Estabrook RW, Cooper DY and Rosenthal O (1963) Biochem. Z. 338: 741-755

4. Orrenius S, Dallner G and Ernster L (1964) Biochem. Biophys. Res. Commun. 14: 329-334

5. Orrenius S (1965) J.Cell Biol. 26: 713-723
6. Orrenius S, Ericsson JLE and Ernster L (1965) J. Cell Biol. 25: 627-639

7. Orrenius S (1965) J. Cell Biol. 26: 725-733

8. Orrenius S and Ericsson JLE (1966) J. Cell Biol. 28: 181-198

9. Mitchell JR et al. (1973) J. Pharmacol. Exp. Ther. 187: 211-217

10. Moldéus $P$ et al. (1974) Eur. J. Biochem. 46: 351-360

11. Jones DP et al. (1979) J. Biol. Chem. 254: 2787-2792

12. Thor $\mathrm{H}$ et al. (1982) J. Biol. Chem. 257: 12419-12425

13. Mirabelli $F$ et al. (1988) Arch. Biochem. Biophys. 264: 261-269

14. Jewell S et al. (1982) Science 217: 1257-1259

15. Nicotera P et al. (1989) Proc. Natl. Acad. Sci. USA 86: 453-457

16. Thor H, Hartzell P and Orrenius S (1984) J. Biol. Chem. 259: 6612-6615

17. Jones DP et al. (1989) J. Biol. Chem. 264: 6398-6403

18. Kerr JF, Wyllie AH and Currie AR (1972) Br. J. Cancer 26: 239-257

19. McConkey DJ et al. (1989) Arch. Biochem. Biophys. 269: 365-370

20. Wyllie AH (1980) Nature 284: 555-556

21. Orrenius S, Zhivotovsky B and Nicotera P (2003) Nat. Cell Biol. 4: 552-565

22. Liu $X$ et al. (1997) Cell 89: 175-184

23. Enari $\mathrm{M}$ et al. (1998) Nature 391: 434-450

24. Schlegel J et al. (1996) J. Biol. Chem. 271: 1841-1844

25. Van den Dobbelsteen DJ et al. (1996) J. Biol. Chem 271: 15420-15427

26. Nobel CS et al. (1995) J. Biol. Chem. 270: 26202-26208

27. Li $P$ et al. (1997) Cell 91: 479-489

28. Zhivotovsky B et al. (1998) Nature 391: 449-450

29. Brustugun OT et al. (1998) Cell Death Diff. 5: 660-668

30. Gogvadze V et al. (2001) J. Biol. Chem. 276: 19066-19071

31. Ott M et al. (2002) Proc. Natl. Acad. Sci. USA 99: 1259-1263

32. Iverson SL and Orrenius S (2004) Arch. Biochem. Biophys. 423: 37-46

33. Robertson JD et al. (2004) EMBO Reports 5: 643-648

34. Enoksson M et al. (2005) J. Biol. Chem. 279: 49575-49578

35. Ankarcrona M et al. (1995) Neuron 15: 961-973 